\title{
REFLECTION AND RUN-UP OF TSUNAMI ON QUAY WALL AND BEHAVIOR OF DRIFTED VESSELS DUE TO TSUNAMI
}

\author{
Norimi Mizutani ${ }^{1}$, Tomoaki Nakamura ${ }^{2}$, Toru Koike ${ }^{3}$, and Yukari Koyasu ${ }^{4}$
}

\begin{abstract}
Behaviors of a drifted vessel due to a tsunami and the reflection of the tsunami from a quay wall are investigated in this paper based on experiments and numerical analysis. It is found that the height of the quay wall has a great influence on the reflection, and hence the tsunami run-up. It is also revealed that the vessel can be run up on the apron when the water depth at the quay wall is larger than the draft of the vessel.
\end{abstract}

Keywords: tsunami; drifted vessel; reflection

\section{INTRODUCTION}

Drifted bodies by tsunami waves like vessels and debris may cause secondary damages by collisions with other inland structures. Therefore, it is necessary to understand the characteristics of the drifted bodies for the complete countermeasure against tsunami disasters. In the past few years, researches have been undertaken to investigate behaviors of drifted objects due to tsunamis (e.g., Matsutomi 2009; Ikeno et al. 2006; Inagaki et al. 2008). Yeom et al. (2007, 2008) investigated behaviors of drifted containers and proposed a formula to estimate the collision force by a drifted container. They pointed out that the added mass of a water column pushing the container plays an important role. However, its effect for the vessel could be smaller than that for the container. Although behaviors of large vessels have been investigated by Fujii et al. (2007) and Masuda et al. (2009), behaviors of small vessels have not been discussed adequately compared with large vessels. In this study, laboratory experiments were conducted to investigate behaviors of a small vessel in front of a quay wall due to a tsunami. Then, numerical simulations based on the multi-interface advection and reconstruction solver (MARS) and the immersed boundary (IB) method were also carried out to investigate behaviors of the vessel and their mechanism in detail. Behaviors of a vessel were expected to be influenced by the reflection of a tsunami from the quay wall, and thus the reflection of the tsunami from the quay wall was also investigated in this study.

\section{LABORATORY EXPERIMENTS}

Laboratory model experiments of the $1 / 40$ scale were conducted using a two-dimensional wave tank (30 $\mathrm{m}$ in length, $0.7 \mathrm{~m}$ in width and $0.9 \mathrm{~m}$ in depth). A model of an apron was installed in the wave tank as shown in Fig. 1. The water depth on the horizontal bed was $44.5 \mathrm{~cm}$ and the water depth at the quay wall was $11.5 \mathrm{~cm}$.

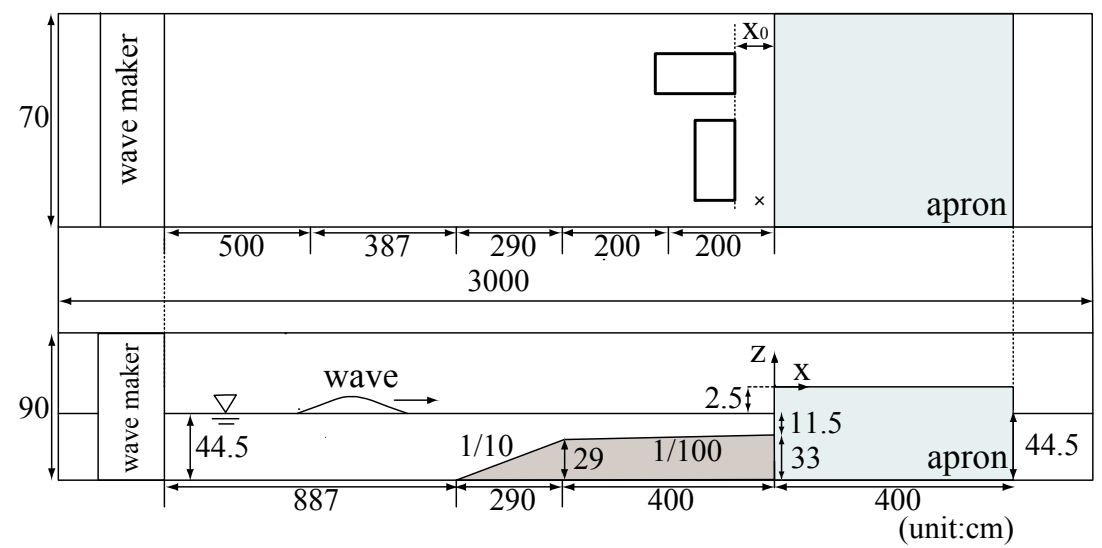

Figure 1. Wave tank and model of apron.

\footnotetext{
${ }^{1}$ Department of Civil Engineering, Nagoya University, Chikusa-ku, Nagoya, Aichi 464-8603, Japan

2 Institute for Advanced Research, Nagoya University, Chikusa-ku, Nagoya, Aichi 464-8601, Japan

${ }^{3}$ Chiba Branch, Shimizu Corporation, Fujimi, Chuo-ku, Chiba, Chiba 260-0015, Japan

${ }^{4}$ Sumitomo Nacco Materials Handling Co., Ltd., Daito-cho, Obu, Aichi 474-0023, Japan
} 
Tsunamis were approximated by long period waves and generated as half-sinusoidal waves by a piston-type wave generator whose maximum stroke was $1.5 \mathrm{~m}$. The period defined as the time duration of wave paddle movement was changed from $T=7.5 \mathrm{~s}$ to $15 \mathrm{~s}$ and the incident wave height (defined as the crest height) was changed from $H i=1.3 \mathrm{~cm}$ to $4.0 \mathrm{~cm}$. The models of vessels were made of acrylic plates and two different shapes and masses were adopted in the experiments as shown in Fig. 2 and Table 1.
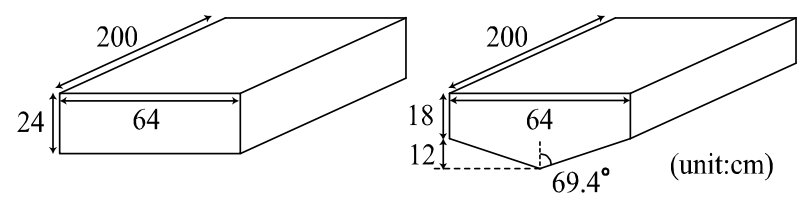

Figure 2. Model of vessels.

\begin{tabular}{|c|c|c|c|c|}
\hline \multicolumn{5}{|c|}{ Table 1. Details of model vessels. } \\
\hline & \multicolumn{2}{|c|}{$\mathrm{G} 1$} & \multicolumn{2}{c|}{$\mathrm{G} 2$} \\
\hline shape & mass $(\mathrm{g})$ & draft $(\mathrm{cm})$ & mass $(\mathrm{g})$ & draft $(\mathrm{cm})$ \\
\hline flat (f) & 93.14 & 0.73 & 170.34 & 1.33 \\
\hline hull (h) & 93.14 & 1.33 & 170.34 & 1.93 \\
\hline
\end{tabular}

Behaviors of the model vessels rested at $x_{0}=0 \mathrm{~cm}, 10 \mathrm{~cm}\left(x_{0}\right.$ : initial distance from the quay wall) and with different orientations (parallel and perpendicular to the quay wall) were investigated and taken with two digital video cameras. Every experimental run was repeated several times.

\section{NUMERICAL SIMULATION}

\section{Simulation method}

The body force type of immersed boundary (IB) method (Yuki et al. 2007) is used to simulate fluid-structure interaction. In the IB method, a structure is presented as a solid volumetric fraction occupying each numerical cell, and velocity inside the structure is controlled by the volumetric fraction. Defining the volume-averaged velocity as $v_{i}=\left(1-F_{o b}\right) v_{i}^{f}+F_{o b} v_{i}^{o b}\left(F_{o b}=\right.$ solid volumetric fraction of the structure $\left(0.0 \leq F_{o b} \leq 1.0\right) ; v_{i}^{f}=$ fluid velocity; $v_{i}^{o b}=u_{i}^{o b}+e_{i j k} \omega_{j}^{o b} r_{k}^{o b}=$ structure velocity; $u_{i}^{o b}=$ structure translation velocity; $\omega_{i}^{o b}=$ angular velocity of the structure; $r_{i}^{o b}=$ relative position vector originating at the structure center of gravity; and $e_{i j k}=$ transposition symbol), a modified Navier-Stokes equation is given as

$$
\frac{\partial v_{i}}{\partial t}+\frac{\partial\left(v_{i} v_{j}\right)}{\partial x_{j}}=-\frac{1}{\hat{\rho}} \frac{\partial p}{\partial x_{i}}-g_{i}+\frac{f_{i}^{s}}{\hat{\rho}}+\frac{\partial}{\partial x_{j}}\left(-\tau_{i j}+2 \hat{v} D_{i j}\right)+Q_{i}-\beta_{i j} v_{j}+f_{i}^{o b}
$$

where $p=$ pressure; $g_{i}=$ gravitational acceleration; $\hat{\rho}=\left(1-F_{o b}\right)\left\{F \rho_{w}+(1-F) \rho_{a}\right\}+F_{o b} \rho_{o b}=$ density; $F=$ volume of fluid (VOF) function representing the volume fraction of water in each cell $(0.0 \leq F \leq 1.0) ; \rho_{w}, \rho_{a}$, and $\rho_{o b}=$ densities of water, air, and the structure; $\hat{v}=\left(1-F_{o b}\right)\left\{F v_{w}+(1-F) v_{a}\right\}+F_{o b} v_{o b}=$ kinematic molecular viscosity; $v_{w}, v_{a}$, and $v_{o b}=$ kinematic molecular viscosity of water, air, and the structure; $f_{i}^{s}=$ surface tension force based on the continuum surface force (CSF) model; $f_{i}^{o b}=$ body force acting on fluids at the interface and inside the structure; $\tau_{i j}=$ turbulent stress based on the dynamic two-parameter mixed model (DTM); $D_{i j}=$ strain rate tensor; $Q_{i}=$ wave source vector; and $\beta_{i j}=$ artificial damping factor matrix. The formulations of $g_{i}, f_{i}^{s}, \tau_{i j}, Q_{i}$, and $\beta_{i j}$ can be found in Nakamura et al. (2008). Using the simplified marker and cell (SMAC; Amsden and Harlow 1970) for time derivative and defining $v_{i}^{p}$ as the predicted seepage velocity vector, the body force at $n$-th time step $f_{i}^{o b n}$ is written as

$$
f_{i}^{o b n}=F_{o b}^{n} \frac{v_{i}^{o b n}-v_{i}^{p 1}}{\Delta t^{n+1 / 2}}
$$

where $\Delta t^{n+1 / 2}=$ time increment between the $n$-th and $(n+1)$-th time steps.

In calculating structure motion, the computation of fluid motion is firstly implemented assuming that the structure is high viscous fluid $\left(v_{o b}=1.0 \mathrm{~cm}^{2} / \mathrm{s}\right)$, and then the value of $F$ is updated with the multi-interface advection and reconstruction solver (Kunugi 2000). Based on Xiao et al. (1997), the 
external force acting on the structure is calculated using the computed values of $p$ and $F_{o b}$. The translation and rotation of the structure are time-integrated using the Newmark $\beta$ method. Unlike Yuki et al. (2007), the value of $F_{o b}$ is calculated based on the linear distance from the center of gravity.

\section{Simulation domain}

Numerical simulation of tsunami reflection and run-up was conducted under the same condition as the laboratory experiment except for the length of the wave tank, as shown in Fig. 3. At the onshore boundary, the no-gradient condition was subjected as the open boundary condition. The finest grid size was $0.25 \mathrm{~cm} \times 0.8 \mathrm{~cm}$ and was applied on the apron, whereas coarser grid sizes were applied to other region to save the computational time and resources.

In the simulation of a drifted vessel, a fine grid size of $0.2 \mathrm{~cm} \mathrm{x} 0.2 \mathrm{~cm}$ was applied to a computational domain of Fig. 4. For this grid size, the computational domain was focused near the quay wall. For this simulation, the propagation of computed incident waves were compared with experimental data, and numerical results of the wave propagation were confirmed to be almost the same as those in the laboratory experiments.

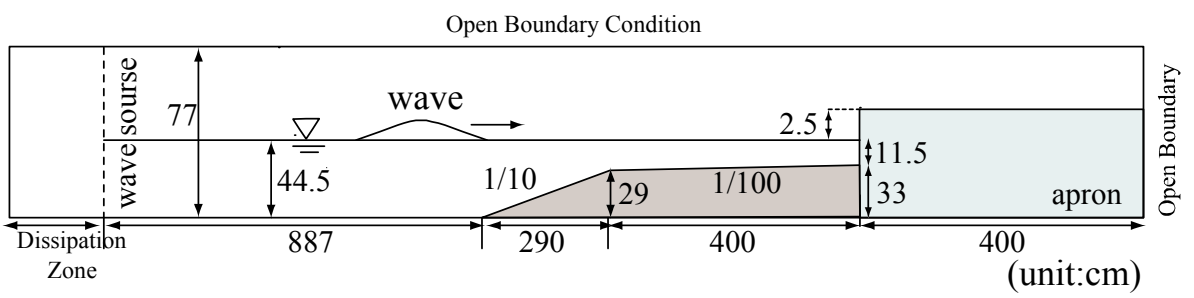

Figure 3. Computational domain for wave reflection and run up.

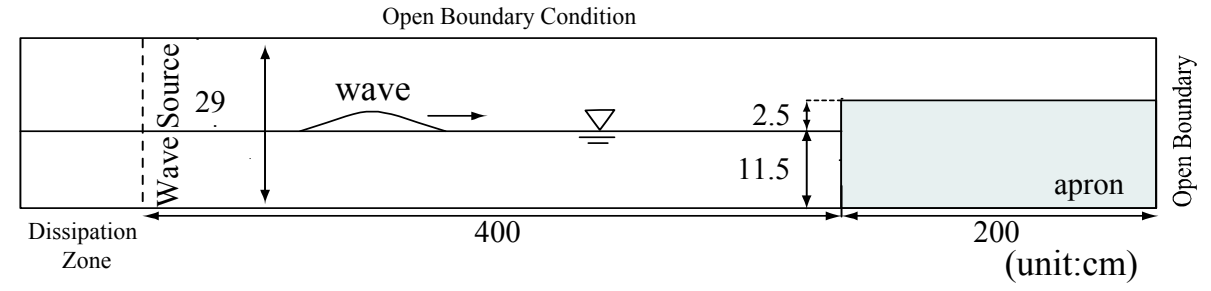

Figure 4. Computational domain for behavior of drifted vessel.

\section{Validation of numerical simulation method}

To verify the numerical simulation method of the present study, computed wave profiles and velocities were compared with measured values in the experiments. The location of wave gages are shown in Fig. 5 and comparison of wave profiles are shown in Fig. 6. Except for the secondary reflected waves, simulated wave profiles agree well with the experimental values and the high performance of the present numerical simulation method is confirmed. Moreover, simulated horizontal velocity on the apron is also compared with the experimental one which is measured with the propeller-type velocimeter as shown in Fig. 7. Although there is small discrepancy between the simulated and measured values at the initial peak value, simulated velocity profile can be judged in good agreement with the measured one.

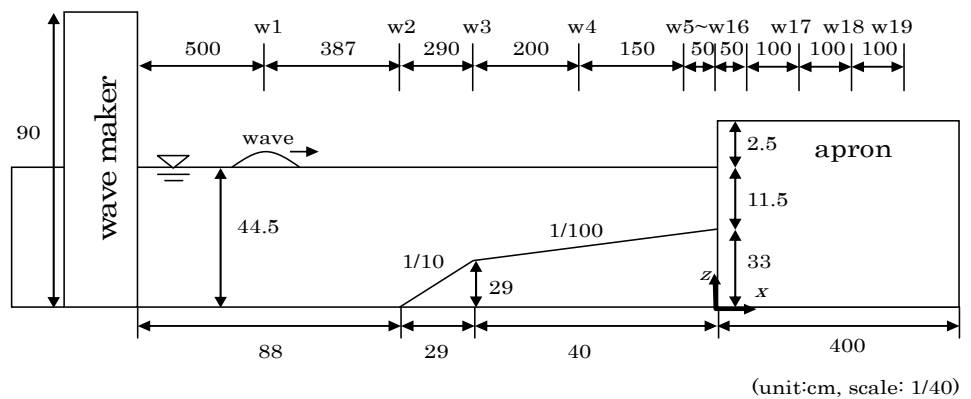

Figure 5. Location of wave gages in numerical simulation. 


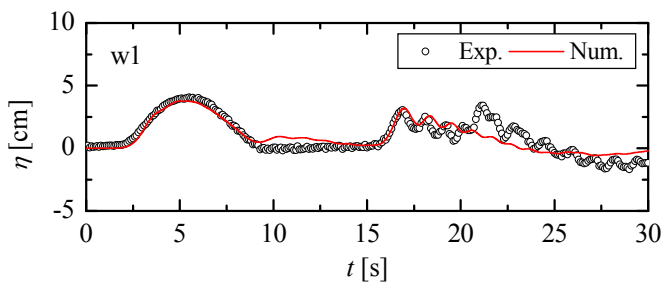

(a) w1

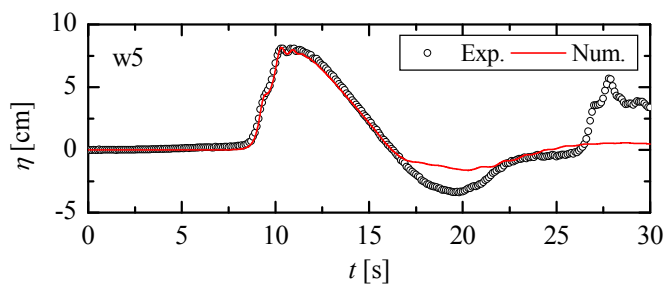

(c) w5

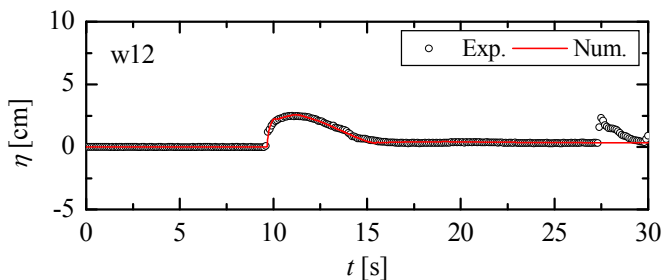

(e) w12

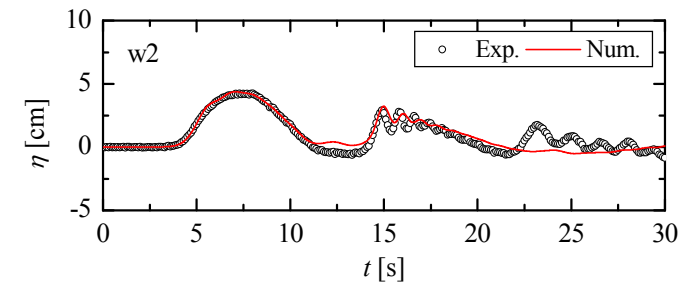

(b) w2

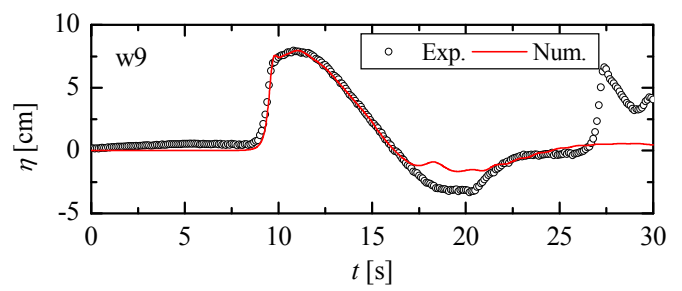

(d) w9

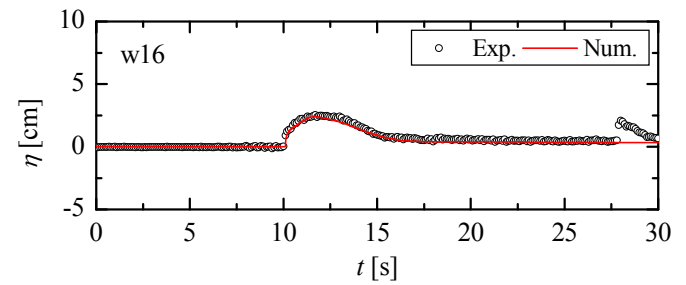

(f) $w 16$

Figure 6. Comparison of water surface profiles.

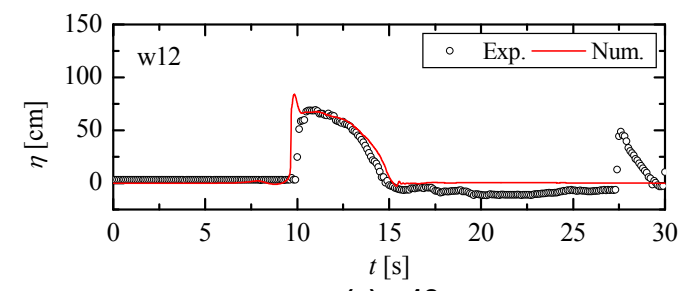

(a) w12

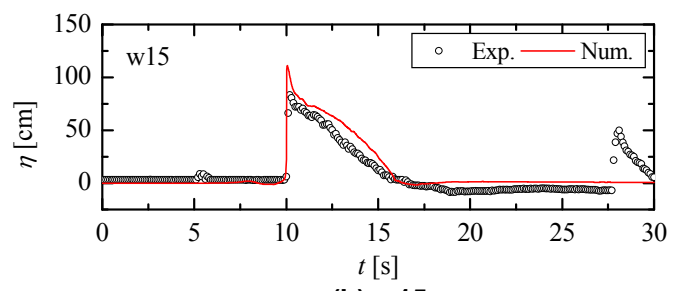

(b) w15

Figure 7. Comparison of horizontal velocity on the apron.

\section{REFLECTION AND RUN-UP OF TSUNAMI}

Run-up of vessels due to a tsunami is closely related to the run-up of a tsunami, consequently to the reflection of a tsunami from the quay wall. However, the reflection of long period waves like a tsunami has not been investigated so much. Thus, the reflection of a tsunami is investigated in this section based on the numerical simulation. An estimation method of the reflected component of a tsunami has not been established yet, and hence the reflected tsunami is defined as the difference between a tsunami computed with the apron and that computed without the apron as shown in Fig. 8.

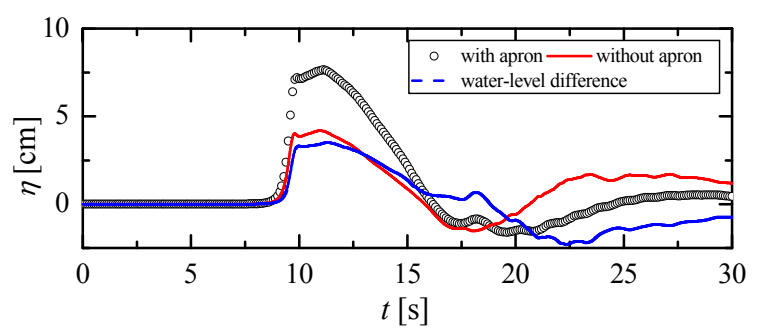

Figure 8. Incident and reflected components of tsunami. 
Reflection coefficient $\mathrm{Kr}$ is defined as $\mathrm{Kr}=\mathrm{Hr} / \mathrm{Hi}$, where $\mathrm{Hi}$ and $\mathrm{Hr}$ are the wave heights of the incident and reflected tsunami waves measured at $10 \mathrm{~cm}$ off the quay wall, respectively. Figure 9 shows variations of $K r$ with $H i$ and $R$ (free board). As seen in the figure, the reflection coefficient $K r$ is 1.0 corresponding to the complete reflection when the wave height (the crest height) $H i$ is less than the free board $(R=2.5 \mathrm{~cm})$, nevertheless of the wave period. Once the crest height exceeds the free board, wave run-up occurs and $K r$ decreases with increasing the crest height $H i$. This result indicates the effectiveness of a countermeasure by increasing the free board to reduce the run-up of tsunamis. As shown later, the authors confirmed that the vertical wall at the quay wall can reduce the run-up of tsunamis from numerical results.

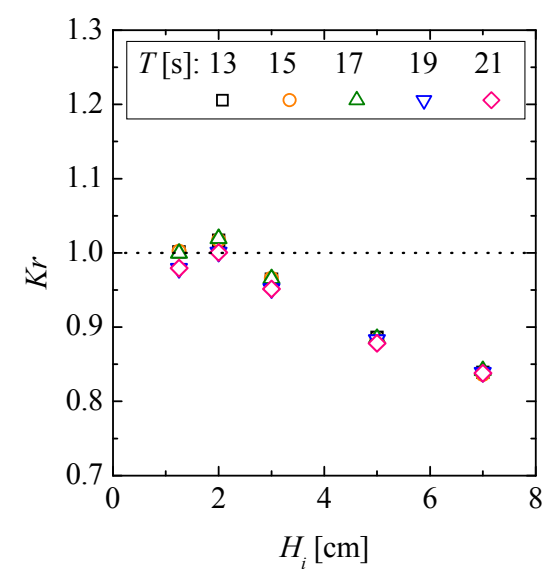

(a) Effect of $\mathrm{Hi}$

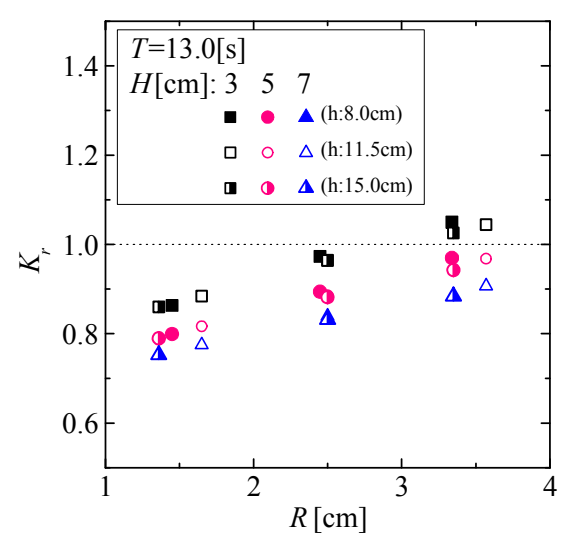

(b) Effect of $\mathbf{R}$

Figure 9. Variations of $\mathrm{Kr}$ with $\mathrm{Hi}$ and $\mathrm{R}$.

\section{BEHAVIOR OF VESSEL DRIFED BY TSUNAMI}

Motion of drifted vessel

Figure 10 shows a behavior of a vessel which is drifted onto the apron. In the figure, Fig. 10(a) shows the trajectory of the top surface of the vessel and Fig. 10(b) shows relationship between the horizontal location of the offshore end of the vessel and the drifting horizontal velocity. The water level in front of the quay wall rises as a tsunami approaches, then the vessel is lifted. Once the keel of the vessel becomes higher than the apron, the vessel starts to be drifted on the apron. The horizontal velocity of the drifting vessel increases rapidly after the vessel begins to be drifted on the apron, and then it approaches to a constant value.

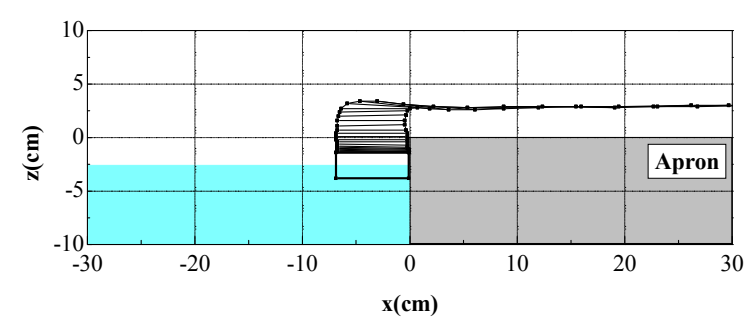

(a) Trajectory of a drifted vessel

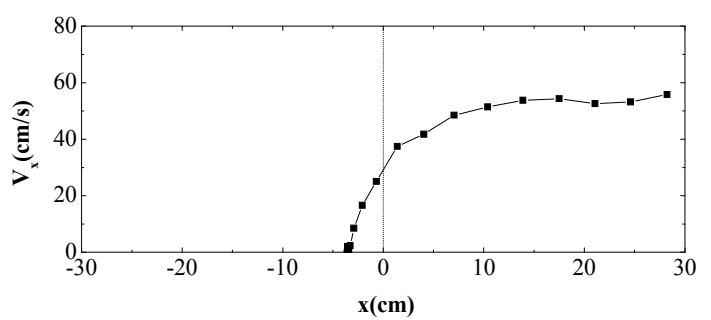

(b) Relationship between $x$ and $\mathrm{Vx}$

Figure 10. Motion on a vessel in front of a quay wall (G1-f, $\left.x_{0}=0 \mathrm{~cm}, \mathrm{Hi}=3.5 \mathrm{~cm}, \mathrm{~T}=10.0 \mathrm{~s}\right)$.

Considering the velocity distribution of a run-up tsunami shown in Fig. 11 and the variation of the horizontal velocity near the water surface of the run-up tsunami shown in Fig. 12, it is seen that the velocity vector turns its direction upward in front of the quay wall, and then it is accelerated if the tsunami runs up on the apron. These results are closely related to the behavior of the drifted container (Fig. 10(b)). 


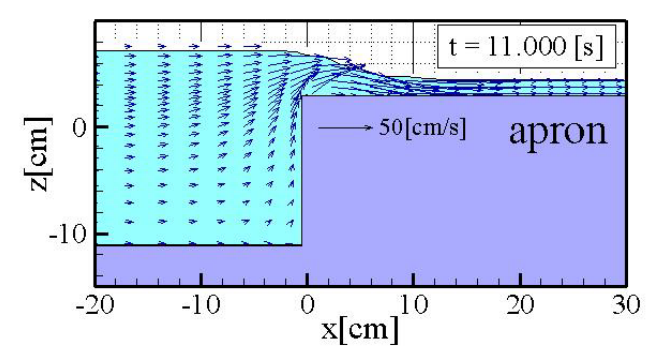

Figure 11. Calculation result of a velocity vector distribution of run up tsunami.

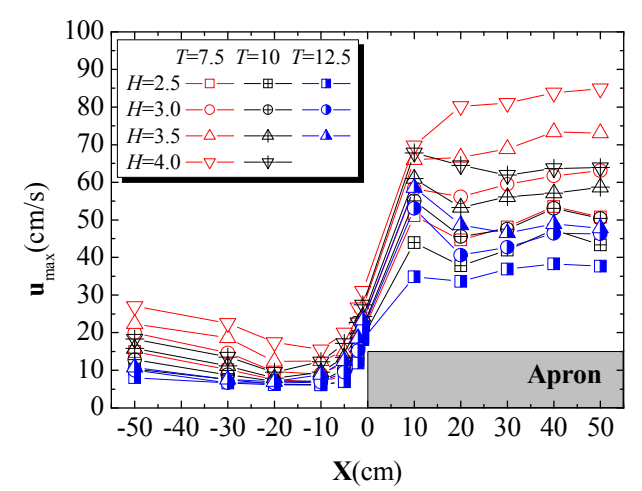

Figure 12. Variation of a horizontal velocity near water surface of run up tsunami.

\section{Velocity of drifted vessel}

Figure 13 shows variations of the horizontal velocity of various vessel models on the apron. Among four models, G1-f, G1-h and G2-f are drifted at almost same velocity. Then, the G2-f and G1$\mathrm{h}$ models touch the apron surface and their velocity rapidly decreases at $x=100 \mathrm{~cm}$ and $150 \mathrm{~cm}$, respectively. These results indicate that although the drifting velocity is not affected by the hull shape, the velocity is significantly affected if the keel touches the apron surface. It is noted that the vessel touching the apron floats again if the water depth increases, and it is drifted again like the G2-f model in Fig. 13.

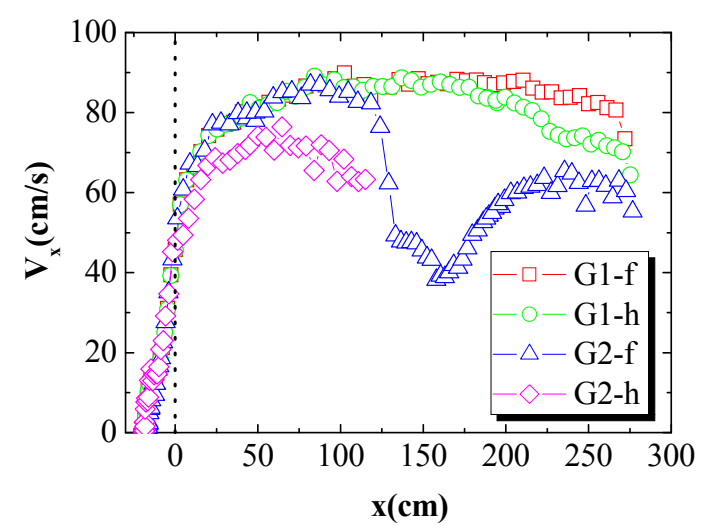

Figure 13. Horizontal velocity of drifted vessels with different shapes and masses.

Relationship between the water particle velocity on the apron and the velocity of a drifted vessel at the same location for the G1-f model is shown in Fig. 14(a), in which the authors does not plot the cases that the vessel model touches the apron surface because the velocity of the model decreases as explained in Fig. 13. It is seen that the vessel is drifted at almost the same velocity as the water particle of the run-up tsunami. Similar relationship obtained in front of the quay wall is shown in Fig. 14(b). Different from the case on the apron, the velocity of the drifted vessel tends to be larger than the water particle velocity in the vicinity of the quay wall. The reason for this will be discussed later. 


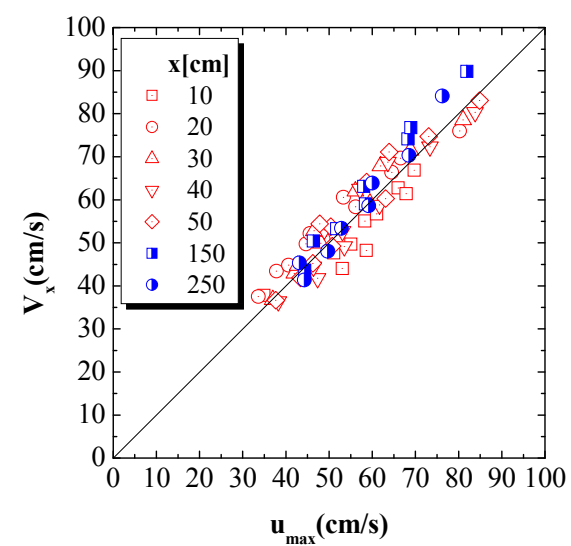

(a) On the apron

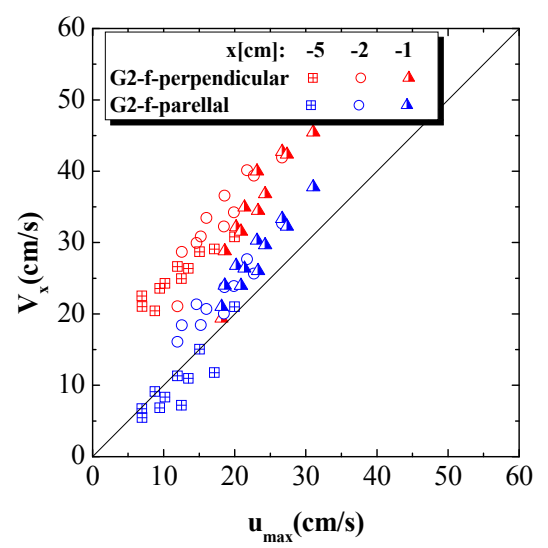

(b) Near quay wall

Figure 14. Relationship between water particle velocity and velocity of drifted vessel $\left(x_{0}=10 \mathrm{~cm}\right.$, parallel).

\section{Numerical simulation of drifted vessel}

The numerical simulation method adopted in this study is demonstrated in this section by comparing simulated results with experimental ones. Figure 15 shows comparison between simulated and measured results of a trajectory of the center of gravity of a vessel model and relationship between its vertical location and velocity. From the figures, the present numerical simulation gives good estimation of the behavior of the drifted vessel, which indicates the validity of the present numerical simulation method.

Figure 16 shows a snapshot of the vessel passing over the quay wall together with pressure contour lines. It is seen that the vessel is drifted by the leading part of the run-up tsunami, where the pressure contour lines are not horizontal. Thus, the buoyant force acting on the vessel has a forwarding force component. This may accelerate the horizontal motion of the vessel. This may be a reason why the drifting velocity of the vessel near the quay wall is larger than the water particle velocity as seen in Fig. 14(b).

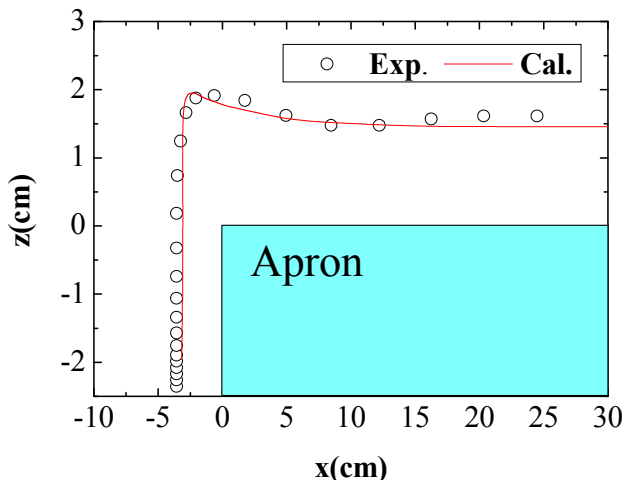

(a) Trajectory of vessel

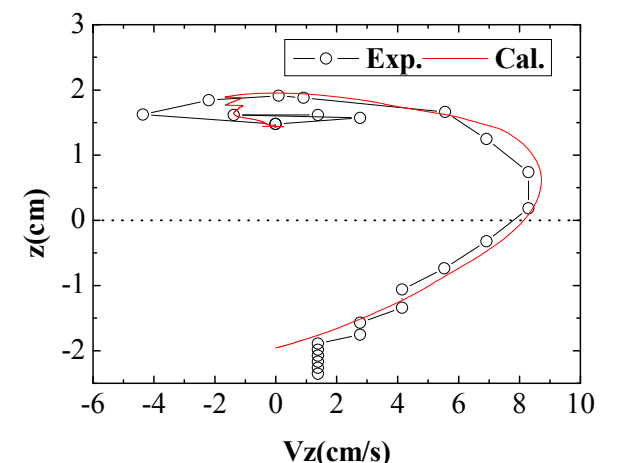

(b) Relationship between vertical location and velocity.

Figure 15. Comparison between simulated results and experimental results $(\mathrm{Hi}=3.0 \mathrm{~cm}, \mathrm{~T}=7.5 \mathrm{~s}, \mathrm{G} 1-\mathrm{f}$, parallel, $\left.x_{0}=0 \mathrm{~cm}\right)$.

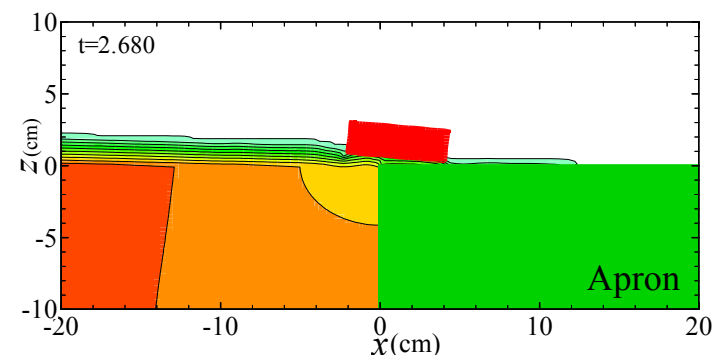

Figure 16. Snapshot of a drifted vessel passing over the quay wall $\left(\mathrm{Hi}=3.5 \mathrm{~cm}, \mathrm{~T}=7.5 \mathrm{~s}, \mathrm{G1}-\mathrm{f}\right.$, parallel, $\mathrm{x}_{0}=$ $0 \mathrm{~cm})$. 


\section{CONDITION OF VESSEL RUN-UP ONTO APRON}

For a countermeasure against the disaster caused by drifted vessels, it is important to discuss the condition for vessels to run up onto apron. In the experiments, this condition is observed by conducting the experiments for various wave heights. Figure 17 shows experimental results where the run-up of a vessel was observed. Similar investigation is conducted based on numerical simulation results and plotted in the same figure. In the figure, $H_{0}$ is the crest height at the quay wall and $D$ is the draft of the vessel.

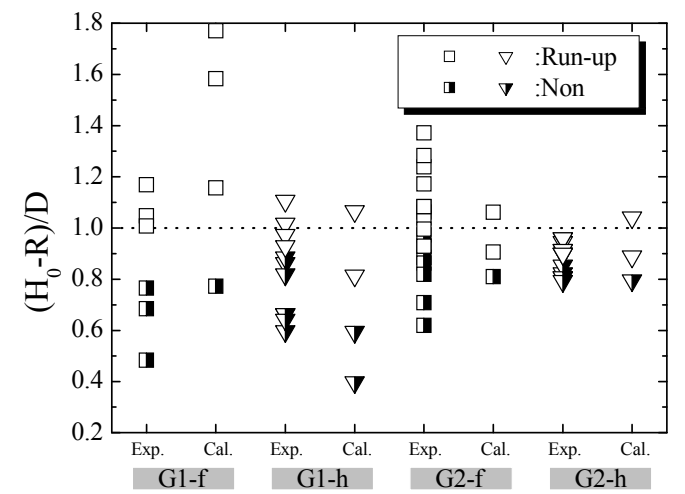

Figure 17. Critical condition for run up of a drifted vessel (parallel).

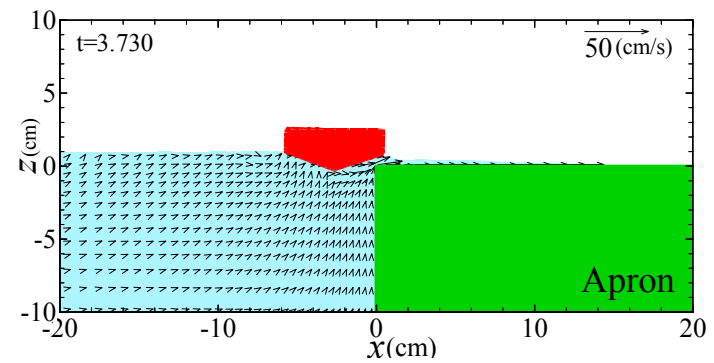

(a) $\mathrm{t}=3.73 \mathrm{~s}$

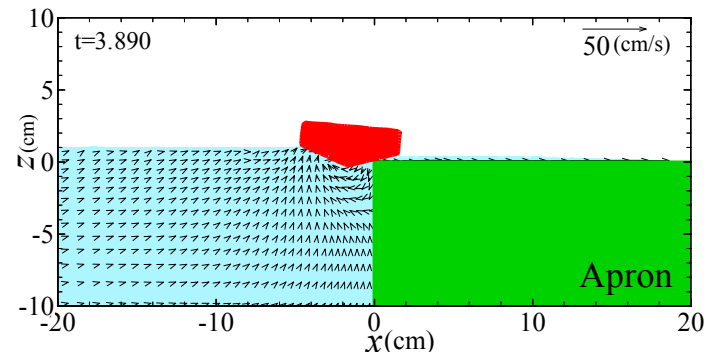

(b) $\mathrm{t}=3.89 \mathrm{~s}$

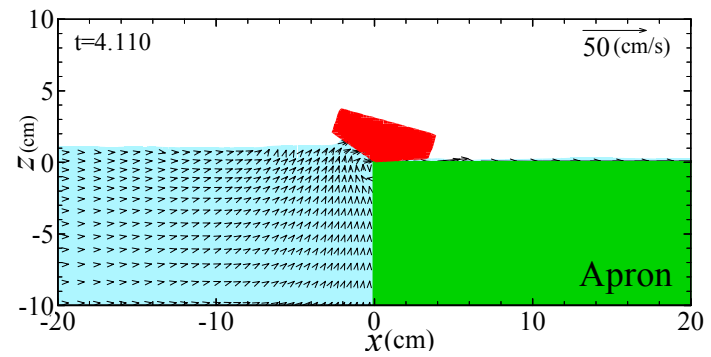

(c) $\mathrm{t}=4.11 \mathrm{~s}$

Figure 18. Snapshots of drifted vessel (h-type, parallel).

From the figure, it is observed that a vessel tends to run up onto the apron when the water depth at the leading edge of the apron exceeds the draft of the vessel. In the figure, only the results for a vessel parallel to the quay wall are shown, however quite similar results are obtained for cases of a vessel placed perpendicular to the quay wall. In case of a vessel of h-type (see Fig. 2), its run-up is observed 
for smaller crest height conditions. Figure 18 shows snapshots of a h-type vessel running up onto the apron. A roll motion of the vessel occurs in the run-up process, which enables to run up in spite of the smaller crest height of the incident wave. This indicates that the critical condition may be underestimated for considering only the draft of the vessel and the excess water depth at the quay wall.

\section{CONCLUSIONS}

Conclusions obtained in this paper are summarized as follows:

1) Reflection of a tsunami depends on the ratio of the wave height to the free board, $R$, and it decreases with increasing the incident wave height if it exceeds the free board. Thus, the installation of a vertical wall at the leading edge of the apron can be an effective measure to reduce the run-up tsunami, and therefore the disaster caused by the run-up tsunami.

2) A vessel in front of the quay wall is first raised by vertical water particle motion due to the incident and reflected waves. Then, it runs up by the tsunami wave if the keel becomes higher than the apron surface. These behaviours are well predicted using the present numerical simulation, which indicates the validity of the present simulation method.

3) Horizontal velocity of the drifted vessel is rapidly increased when it passes the leading edge of the quay wall. At that time, drifting velocity often exceeds the water particle velocity due to the buoyant force which acts obliquely upward. Then it approaches to the run-up wave velocity. If the bottom of the vessel touches the apron surface, the drifting velocity is reduced.

4) The vessel is confirmed to run up onto the apron by a tsunami if the run-up wave height at the leading edge is nearly equal or larger than the draft of the vessel, $D$. Numerical simulation results for vessel motion show almost the same as experimental data. The critical depth of whether the vessel runs up onto the apron depends on the shape of the hull because roll motion lessens the critical wave height for the vessel with inclined hull shape.

\section{ACKNOWLEDGMENTS}

This study is conducted under the support of the Grant-in-Aid for Scientific Research, JSPS (19360222) and the authors express their thanks to this support.

\section{REFERENCES}

Amsden, A. A. and F. H. Harlow. 1970. A simplified MAC technique for incompressible fluid flow calculation, Journal of Computational Physics, 6, 322-325.

Fujii, N., T. Fukuyama, S. Inagaki, T. Ikeya, K. Yanagisawa, and M. Oomori. 2007. Experimental study on variability in drifting behavior due to tsunami and its evaluation method, Annual Journal of Coastal Engineering, JSCE, 54, 241-245 (in Japanese).

Ikeno, M., N. Mori, and H. Tanaka. 2001. Experimental study on tsunami force and impulsive force by a drifter under breaking bore like tsunamis, Proceedings of Coastal Engineering, JSCE, 48, 846850 (in Japanese).

Inagaki, S., T. Ikeya, M. Omori, N. Fujii, T. Mukohara, and K. Hatayama. 2008. Model experiment and simulative prediction on slipping and drifting of oil storage tank by tsunami, Annual Journal of Coastal Engineering, JSCE, 55, 276-280 (in Japanese).

Kunugi, T. 2000. MARS for multiphase calculation, CFD Journal, 9(1), IX-563.

Masuda, M., K. Masuda, T. Ikoma, and H. Maeda. 2009. A study on prediction of behavior of floating structures in the vicinity of a wharf induced by tsunamis, Annual Journal of Civil Engineering in the ocean, 25, 81-86 (in Japanese).

Matsutomi, H. 2009. Contribution of dynamic pressure to fluid force and probability distribution of collision force of floating bodies due to tsunami inundated flow, Annual Journal of Coastal Engineering, JSCE, 56, 836-840 (in Japanese).

Nakamura, T., Y. Kuramitsu, and N. Mizutani. 2008. Tsunami scour around a square structure, Coastal Engineering Journal, JSCE, 50(2), 209-246.

Xiao, F., T. Yabe, T. Ito, and M. Tajima. 1997. An algorithm for simulating solid objects suspended in stratified flow, Computer Physics Communications, 102, 147-160.

Yuki, Y., S. Takeuchi, and T. Kajishima. 2007. Efficient immersed boundary method for strong interaction problem of arbitrary shape object with the self-induced flow, Journal of Fluid Science and Technology, JSME, 2(1), 1-11. 
Yeom, G. S., T. Nakamura, A. Usami, and N. Mizutani. 2008. Study on estimation of collision force of a drifted container using fluid-structure interaction analysis, Annual Journal of Coastal Engineering, JSCE, 55, 281-285 (in Japanese).

Yeom, G. S., N. Mizutani, K. Shiraishi, A. Usami, S. Miyajima, and T. Tomita. 2007. Study on behavior of drifting containers due to tsunami and collision forces, Annual Journal of Coastal Engineering, JSCE, 54, 851-855 (in Japanese). 